\title{
JUN Amino-Terminal Kinase 1 Signaling in the Proximal Tubule Causes Cell Death and Acute Renal Failure in Rat and Mouse Models of Renal Ischemia/Reperfusion Injury
}

Keren Grynberg, ${ }^{* \dagger}$ Elyce Ozols, ${ }^{* \dagger}$ William R. Mulley, ${ }^{* \dagger}$ Roger J. Davis, ${ }^{\ddagger}$ Richard A. Flavell, ${ }^{\S}$ David J. Nikolic-Paterson, ${ }^{* \dagger}$ and Frank Y. Ma*t

From the Department of Nephrology, ${ }^{*}$ Monash Medical Centre, Clayton, Victoria, Australia; the Centre for Inflammatory Diseases, ${ }^{\dagger}$ Monash University, Clayton, Victoria, Australia; the Howard Hughes Medical Institute and Program in Molecular Medicine, ${ }^{\ddagger}$ University of Massachusetts Medical School, Worcester, Massachusetts; and the Department of Immunobiology, ${ }^{\S}$ Yale University School of Medicine, New Haven, Connecticut

\author{
Accepted for publication \\ February 4, 2021. \\ Address correspondence to \\ David J. Nikolic-Paterson, \\ D.Phil., Department of \\ Nephrology, Monash Medical \\ Centre, 246 Clayton Rd., Clay- \\ ton, VIC 3168, Australia. E- \\ mail: david.nikolic-paterson@ \\ monash.edu.
}

\begin{abstract}
Activation of the JUN amino-terminal kinase (JNK) pathway is prominent in most forms of acute and progressive tubulointerstitial damage, including acute renal ischemia/reperfusion injury (IRI). Two forms of JNK, JNK1 and JNK2, are expressed in the kidney. Systemic administration of pan-JNK inhibitors suppresses renal IRI; however, the contribution of JNK1 versus JNK2, and the specific role of JNK activation in the proximal tubule in IRI, remains unknown. These questions were addressed in rat and mouse models of acute bilateral renal IRI. Administration of the JNK inhibitor, CC-930, substantially reduced the severity of renal failure, tubular damage, and inflammation at 24 hours in a rat IRI model. Additionally, Jnk1 ${ }^{-/-}$mice, but not $\mathrm{Jnk} 2^{-/-}$mice, were shown to be significantly protected against acute renal failure, tubular damage, and inflammation in the IRI model. Furthermore, mice with conditional Jnk1 deletion in the proximal tubule also showed considerable protection from IRI-induced renal failure, tubular damage, and inflammation. Finally, primary cultures of Jnk1 ${ }^{-/-}$, but not Jnk2 ${ }^{-{ }^{-}}$, tubular epithelial cells were protected from oxidant-induced cell death, in association with preventing phosphorylation of proteins (receptor interacting serine/threonine kinase 3 and mixed lineage kinase domain-like pseudokinase) in the necroptosis pathway. In conclusion, JNK1, but not JNK2, plays a specific role in IRI-induced cell death in the proximal tubule, leading to acute renal failure. (Am J Pathol 2021, 191: 817-828; https://doi.org/10.1016/j.ajpath.2021.02.004)
\end{abstract}

Renal ischemia/reperfusion injury (IRI) is a common cause of acute kidney injury (AKI), which involves a partial or complete cessation of blood flow to the kidney with subsequent restoration of the circulation and re-oxygenation. This can occur in various settings, including kidney transplantation, cardiopulmonary bypass surgery, and severe hypotension associated with major blood loss or sepsis. ${ }^{1}$ Ischemia results in a mismatch between oxygen supply and demand in local tissues, whereas re-oxygenation leads to excess production of oxygen free radicals. The ensuing hypoxia, oxidative stress, and impaired removal of waste result in tubular injury, inflammation, and, in cases of severe injury, cell death. ${ }^{1}$ The pathogenesis of renal IRI is complex and involves direct tubular epithelial cell damage through hypoxia/re-oxygenation and mitochondrial damage, as well as indirect tubular damage via the recruitment and activation of neutrophils and monocyte/macrophages. ${ }^{1,2}$

The JUN amino-terminal kinase (JNK) is a stressactivated protein kinase that regulates cellular responses,

\footnotetext{
Supported by National Health and Medical Research Council of Australia grant 1156982 (D.J.N.-P. and F.Y.M.) and a Royal Australian College of Physicians Jacquot PhD Scholarship (K.G.).

D.J.N.-P. and F.Y.M. contributed equally to this work.

Disclosures: D.J.N.-P. has previously received funding from Celgene for studies on JUN amino-terminal kinase inhibitors.
} 
such as inflammation and cell death. ${ }^{3}$ JNK is extremely sensitive to activation by reactive oxygen species, osmotic stress, and proinflammatory cytokines. Multiple JNK isoforms are encoded by three genes (Jnk1, Jnk2, and Jnk3), of which JNK1 and JNK2 are widely expressed, including in cells of the kidney. ${ }^{3,4}$ JNK facilitates stress-induced mitochondrial-dependent apoptosis and necrosis, ${ }^{5}$ including tubular cell death induced by ATP depletion or reactive oxygen species. ${ }^{6,7}$

Activation of JNK signaling is evident in proximal tubular epithelial cells within 20 to 30 minutes of reperfusion of human kidney allografts. ${ }^{8}$ In a similar manner, JNK is strongly activated in tubular cells at 20 minutes after renal IRI in the rat. ${ }^{8}$ Prophylactic treatment with pan-JNK inhibitors, CC-401 or SP600125, provides considerable protection against tubular damage, leukocyte infiltration, and acute renal failure following IRI in rats. ${ }^{8,9}$ However, these studies do not indicate whether both JNK1 and JNK2 contribute to this injury, as is the case in renal interstitial fibrosis in the obstructed kidney, ${ }^{4}$ or whether only one JNK isoform is involved. In addition, these studies do not define whether JNK signaling in the proximal tubule is primarily responsible for inducing acute renal failure following IRI, or whether JNK signaling in other cell types may also be involved.

This study addressed two important mechanistic questions regarding the role of JNK signaling in IRI. First, is there redundancy between JNK1 and JNK2 in this response? Second, is JNK activation within the proximal tubule sufficient to induce tubular cell damage, inflammation, and acute renal failure?

\section{Materials and Methods}

\section{Reagents}

The following primary antibodies were used: rabbit antibodies against phosphorylated JUN Ser63, cleaved caspase 3 , phosphorylated receptor interacting serine/threonine kinase 3 (RIP3) Thr231/Ser232 and phosphorylated mixed lineage kinase domain-like pseudokinase (MLKL) Ser345 (Cell Signaling, San Diego, CA), rabbit anti- $\gamma$-glutaryl transferase, rat anti-mouse neutrophils (Ly6G), mouse antirat neutrophils (RP1), and mouse anti- $\alpha$-tubulin (Abcam, Melbourne, VIC, Australia). CC-930 is a pan-JNK inhibitor and was provided by Celgene Corp. (San Diego, CA). ${ }^{10,11}$

\section{Animals}

Outbred male Sprague-Dawley rats and inbred male C57BL/6J mice were obtained from the Monash Animal Research Platform (Clayton, VIC, Australia). Mapk8/ Jnk1 $1^{-\prime}$ and Mapk9/Jnk2 $2^{-1-}$ mice on the C57BL/6J background were imported from Jackson Laboratories (Bar Harbor, ME), and validation of the gene knockout is presented in Supplemental Figure S1. Jnk $1^{f f f}$ and $\gamma$-glutamyltransferase $(\gamma \mathrm{GT})-$ Cre recombinase expressing mice
A
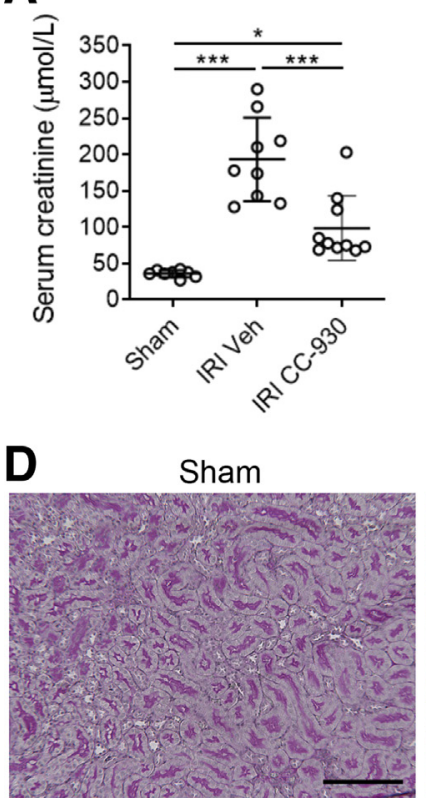

B
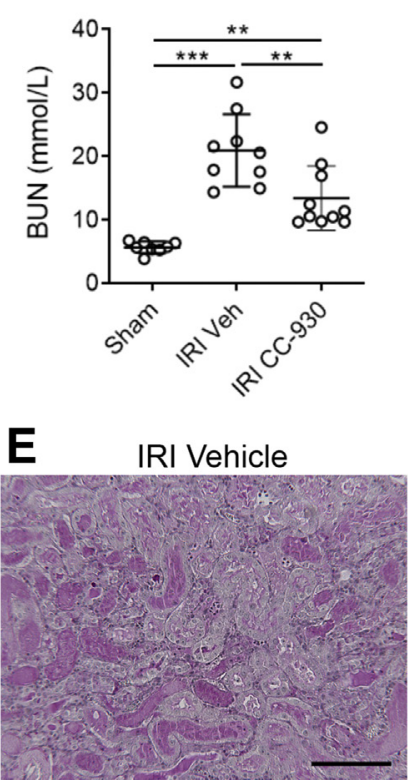

C
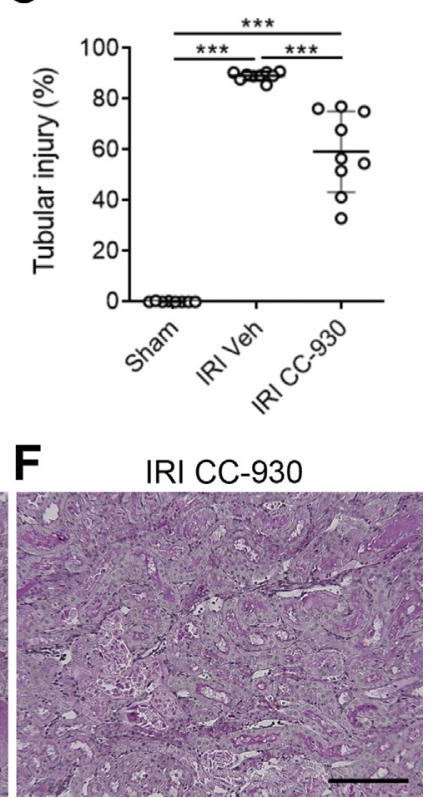

Figure 1 JNK inhibitor treatment reduces acute kidney injury. Groups of vehicle (veh) - and CC-930-treated rats underwent bilateral ischemic/reperfusion injury (IRI), with sham controls. A: Serum creatinine. B: Blood urea nitrogen (BUN). C: Percentage of tubules showing injury. D-F: Periodic acid-Schiff staining of kidney sections. Representative images showing renal histology in D: Sham control with normal renal histology. E: Vehicle-treated IRI with loss of brush border, nuclear loss, sloughing of cells into the lumen, and cast formation, and. F: CC-930-treated IRI with substantial, but reduced, tubular damage. One-way analysis of variance with the Tukey multiple-comparisons test was performed. ${ }^{*} P<0.05,{ }^{*} P<0.01$, and ${ }^{*} * *<0.001$. Scale bars $=100 \mu \mathrm{m}(\mathbf{D}-\mathbf{F})$. 

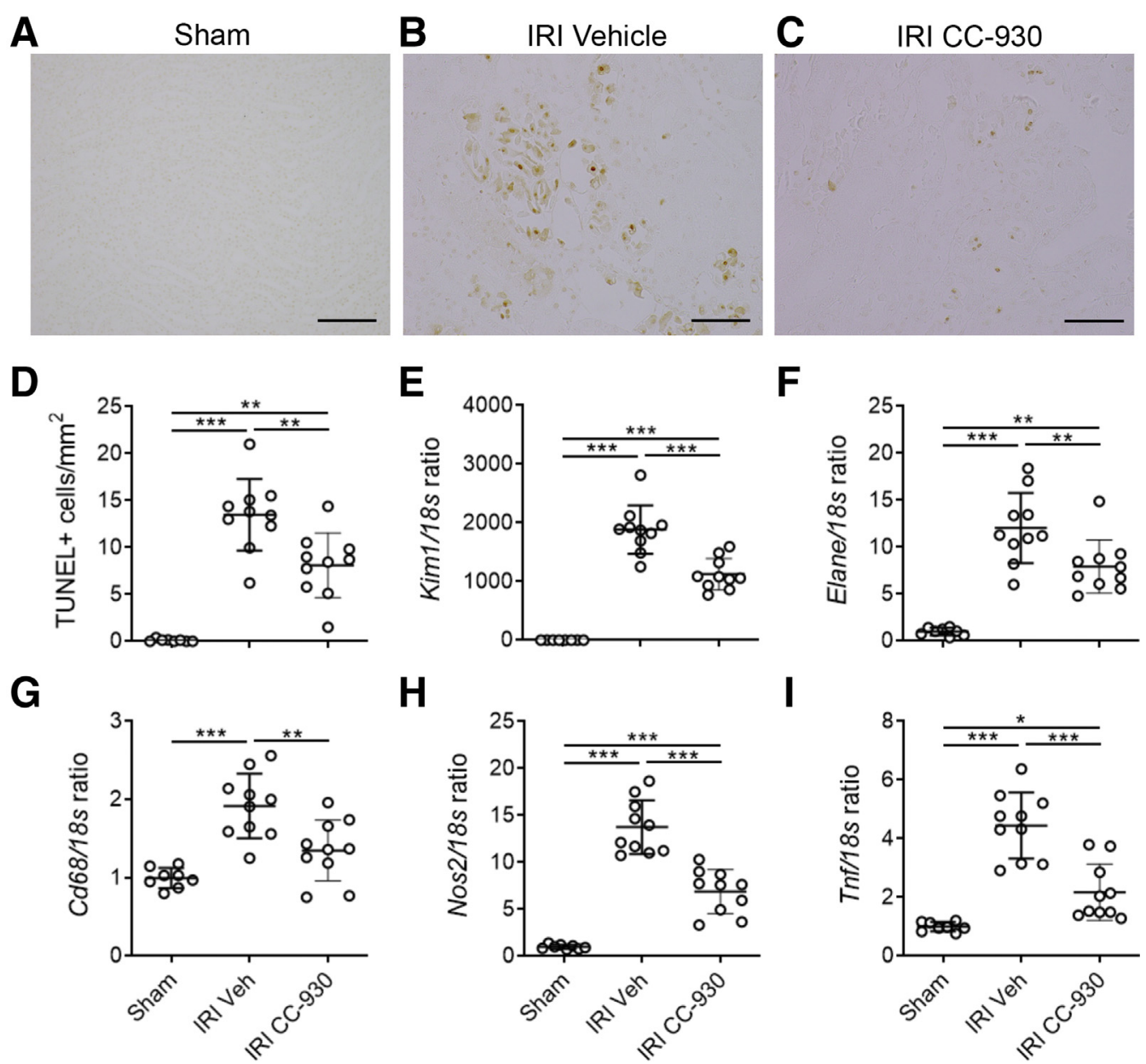

Figure 2 JNK inhibitor treatment reduces tubular cell death and inflammation. Groups of vehicle (veh) - and CC-930-treated rats underwent bilateral ischemic/reperfusion injury (IRI), with sham controls. A-C: Images for terminal deoxynucleotidyl transferase-mediated dUTP nick-end labeling (TUNEL) staining. A: Sham control. B: Vehicle-treated IRI, showing many TUNEL ${ }^{+}$tubular cells. C: CC-930-treated IRI shows a reduction in TUNEL ${ }^{+}$cells. D: Quantification of TUNEL staining. E-I: Real-time PCR analysis of kidney mRNA levels for Kim1/Havcr1 (E), Elane (F), Cd68 (G), Nos2 (H), and Tnf (I). One-way analysis of variance with the Tukey multiple-comparisons test was performed. ${ }^{*} P<0.05$, ${ }^{* *} P<0.01$, and ${ }^{* * *} P<0.001$. Scale bars $=100 \mu \mathrm{m}(\mathbf{A}-\mathbf{C})$.

have been described previously, ${ }^{12,13}$ and were backcrossed at least 12 times onto the C57BL/6J background. Animal studies were approved by the Monash Medical Center Animal Ethics Committee and performed according to the Australian Code of Practice for the Care and Use of Animals for Scientific Purposes.

\section{Bilateral IRI}

Rats underwent bilateral IRI, as previously described. ${ }^{14,15}$ Male rats were anesthetized with ketamine and xylazine. A heating blanket connected to a rectal thermometer was used to maintain body temperature at $37^{\circ} \mathrm{C}$. Following a midline abdominal incision, both renal pedicles were clamped using non-traumatic vascular clamps for 25 minutes, during which the abdomen was temporarily sutured. Clamps were removed, and kidney reperfusion was confirmed visually. The abdomen was sutured in two layers, and saline was provided by s.c. injection. Analgesia involved s.c. injection of $0.05 \mathrm{mg} / \mathrm{kg}$ buprenorphine and 2 to 3 drops of bupivacaine onto the sutures at the end of surgery. Male mice underwent the same bilateral IRI surgical procedure, with a 17 -minute $\left(\mathrm{Jnkl}^{-/-}\right.$study) or a 19-minute $\left(\mathrm{Jnk2^{-/- }}\right.$ and $\mathrm{Jnkl^{fff }}$ $\gamma G T$-Cre study) ischemic time.

Groups of 9 or 10 rats were treated with $60 \mathrm{mg} / \mathrm{kg}$ b.i.d. CC- 930 or vehicle alone $(0.5 \%$ carboxymethylcellulose and $0.25 \%$ Tween-20) by oral gavage, starting 1 hour before surgery and continuing until animals were sacrificed 24 hours after reperfusion. Sham control animals underwent the same surgical procedure, except that the renal pedicles were not clamped. Serum creatinine and blood urea nitrogen levels were measured using a Dupont ARL Analyser (Wilmington, DE) by the Department of Biochemistry, Monash Health.

\section{Analysis of Kidney Damage}

Tubular damage was assessed in the outer medulla on periodic acid-Schiff-stained sections ( $2 \mu \mathrm{m}$ thick) of formalin-fixed tissue. The percentage of tubular cross-sections exhibiting damage was scored under high power $(\times 400)$ : damage was characterized as loss of the brush border, nuclear loss, and 

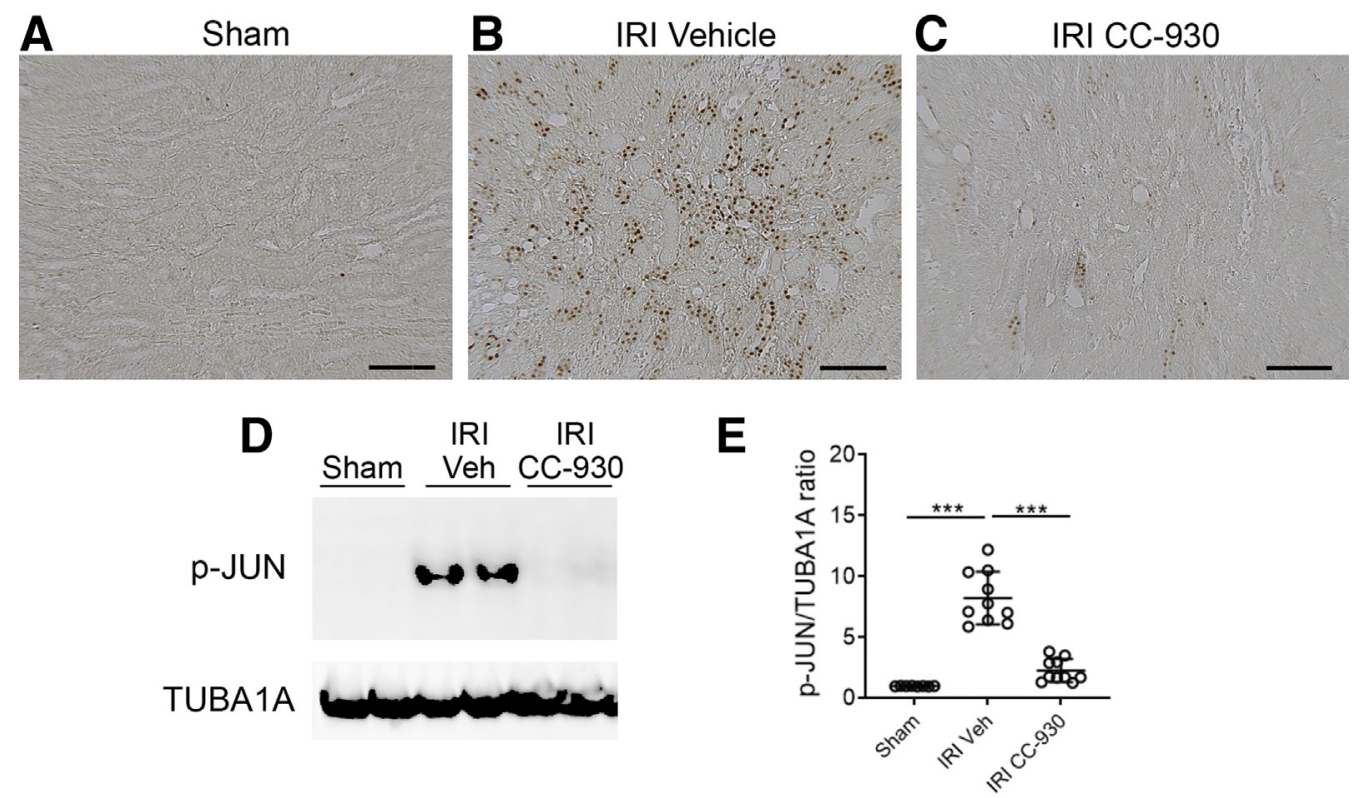

Figure 3 JNK signaling in ischemic/reperfusion injury (IRI). Groups of vehicle (veh) - and CC-930-treated rats underwent bilateral IRI, with sham controls. A-C: Immunostaining of phosphorylated JUN (p-JUN) Ser63. A: Sham control with occasional stained cells. B: Vehicle-treated IRI, showing p-JUN staining in many tubular cells. C: CC-930-treated IRI shows a dramatic reduction in p-JUN-stained cells. D: Western blot analysis for p-JUN Ser63 in kidney lysates with TUBA1A/tubulin loading control. E: Quantification of Western blot analysis. One-way analysis of variance with the Tukey multiple-comparisons test was performed. ${ }^{* *} P<0.001$. Scale bars $=100 \mu \mathrm{m}(\mathbf{A}-\mathbf{C})$.

sloughing of cells into the lumen. The average number of tubular cross-sections scored in the rat model was 1293 per case, and the average number was 1155 per case in the mouse model. In the rat model, cell death was assessed in sections (4 $\mu \mathrm{m}$ thick) of formalin-fixed tissue by terminal deoxynucleotidyl transferase-mediated dUTP nick-end labeling (TUNEL) staining with the ApopTag Peroxidase In Situ Apoptosis Detection Kit (Millipore-Chemicon, Ryde, NSW, Australia). The number of $\mathrm{TUNEL}^{+}$tubular cells in the outer medulla was counted in high-power $(\times 400)$ fields. All scoring was performed on blinded slides (F.Y.M., K.G.).

\section{Immunohistochemistry}

Immunostaining for phosphorylated JUN (p-JUN), cleaved caspase 3 , and $\gamma$ GT was performed on formalin-fixed sections ( $4 \mu \mathrm{m}$ thick) using antigen retrieval with $0.1 \mathrm{~mol} / \mathrm{L}$ sodium citrate, $\mathrm{pH}$ 6.0, and a three-layer avidin-biotin peroxidase complex staining method, as previously described. ${ }^{16}$ Immunostaining for neutrophils was performed on cryostat sections of tissues fixed in $2 \%$ paraformaldehyde-lysine-periodate using a peroxidase-conjugated anti-peroxidase method.

The number of neutrophils and cleaved caspase 3 stained cells was counted in the outer medulla under high power $(\times 400)$. All scoring was performed on blinded slides (K.G., F.Y.M.).

\section{Western Blot Analysis}

Cultured cells or frozen kidney tissue was homogenized in $0.5 \mathrm{~mL}$ of lysis buffer, sonicated, centrifuged, and processed for Western blot analysis, as previously described. ${ }^{17}$ Blots were incubated with antibodies to phosphorylated JUN, phosphorylated RIP3, phosphorylated MLKL, or $\alpha$-tubulin antibodies, which were detected with goat anti-rabbit Alexa Fluor 680 or donkey anti-mouse IRDye 800 secondary antibodies (Thermo Fisher Scientific, Scoresby, VIC, Australia) using the Odyssey Infrared Image Detecting System (LICOR, Lincoln, NE). Densitometry analysis used ImageJ software version 1.51r (NIH, Bethesda, MD; https://imagej. nih.gov/ij).

\section{Real-Time PCR}

RNA was extracted from frozen kidney samples with the Ambion RiboPure Kit (Thermo Fisher Scientific) and reverse transcribed with random primers using the SuperScript III First-Strand Synthesis System (Thermo Fisher Scientific). The PCR was performed using a StepOne Real-Time PCR system (Thermo Fisher Scientific) using TaqMan probes. The primer/ probes for Nos 2 and Tnf have been described previously, ${ }^{18}$ and the other primer/probes were purchased from Thermo Fisher Scientific. All amplicons were normalized against $18 \mathrm{~S}$ in the same reaction, and the relative amount of mRNA was determined using the comparative cycle threshold $(\Delta \mathrm{Ct})$ method.

\section{Primary Tubular Epithelial Cell Culture}

Tubular cells were isolated from the kidney of normal $J n k 1^{-/}, J n k 2^{-/-}$, and wild-type (WT) mice and cultured on collagen-coated plates, as previously described. ${ }^{19}$ To measure cell death, cells were starved in $1 \%$ fetal calf serum for 18 hours, and then varying concentrations of hydrogen peroxide were added for 24 hours. Cells then were analyzed 

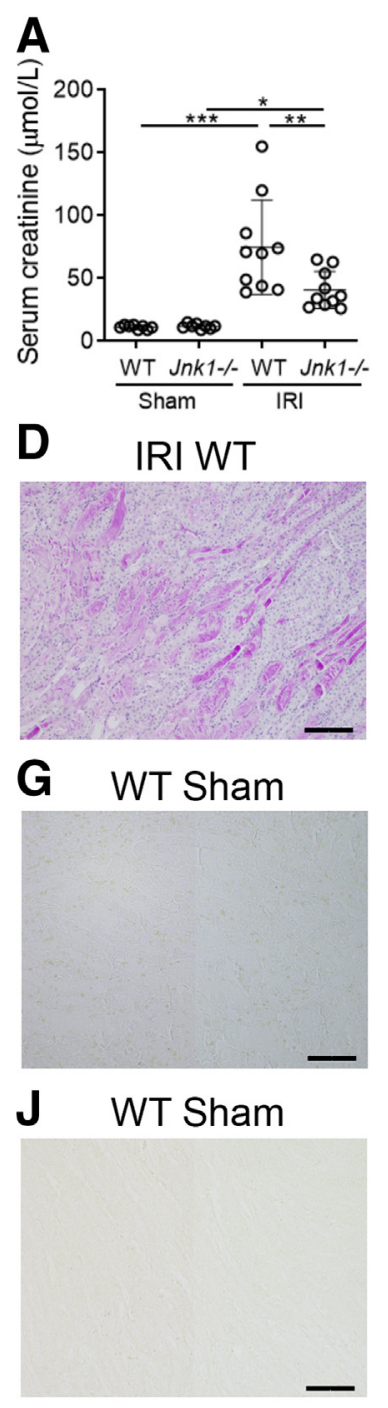

M

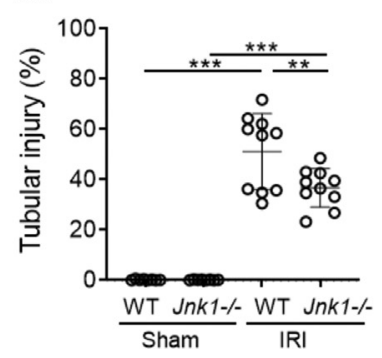

B
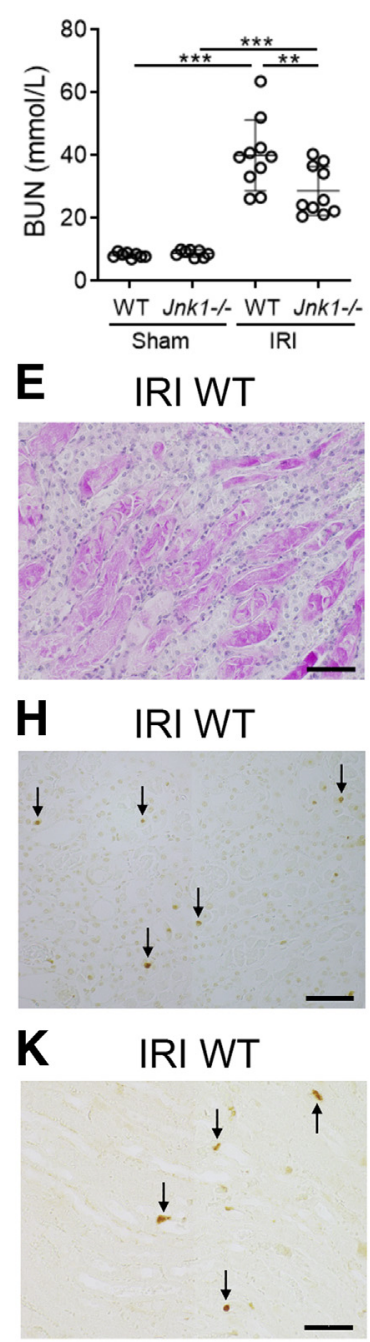

N

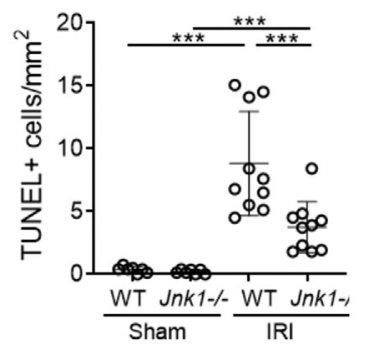

C

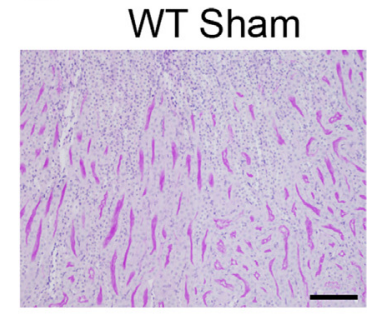

F IRI Jnk1-/-

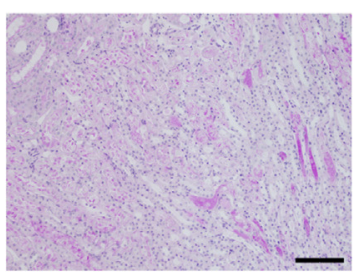

I IRI Jnk1-/-

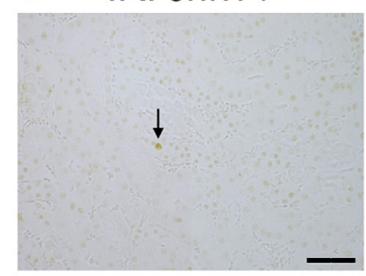

L IRI Jnk1-/-
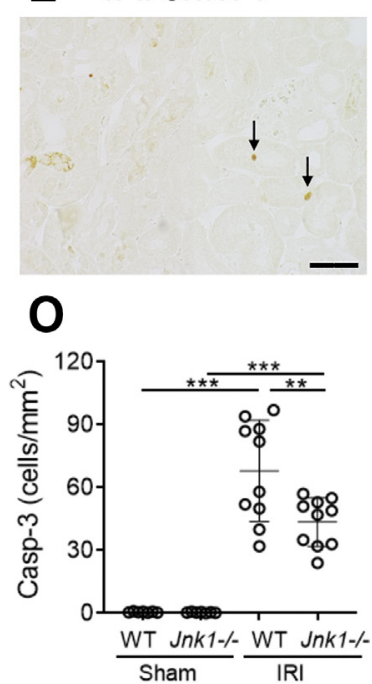

Figure 4 JNK1 promotes acute kidney injury. Groups of wild-type (WT) and Jnk1 ${ }^{-1-}$ mice underwent bilateral ischemic/reperfusion injury (IRI), or a sham procedure. A: Serum creatinine. B: Blood urea nitrogen (BUN). C-F: Periodic acid-Schiff staining of kidney sections. C: WT sham control, showing normal renal histology. D: WT IRI, showing considerable tubular damage with loss of brush border, nuclear loss, sloughing of cells into the lumen, and cast formation. E: Higher-power field of D. F: Jnk1 ${ }^{-1-}$ IRI shows significant, but reduced, tubular damage. G-I: Terminal deoxynucleotidyl transferase-mediated dUTP nick-end labeling (TUNEL) staining (examples of stained cells shown by arrows). G: WT sham control lacks TUNEL staining. H: WT IRI shows multiple TUNEL-stained cells. I: Jnk1 ${ }^{-/-}$ IRI shows a reduction in TUNEL-stained cells. $\mathbf{J}$ -L: Cleaved caspase 3 staining (examples of stained cells shown by arrows). J: WT sham control lacks staining. K: WT IRI shows multiple cells stained for cleaved caspase 3 (Casp-3). L: Jnk1 $1^{-/}$IRI shows a reduction in stained cells. M: Percentage of tubules showing injury. N: Quantification of TUNEL staining. 0: Quantification of cleaved caspase 3-stained cells. Oneway analysis of variance with the Tukey multiple-comparisons test was performed. ${ }^{*} P<0.05,{ }^{*} * P<0.01$, and ${ }^{* * *} P<0.001$. Scale bars: $100 \mu \mathrm{m}$ (C, D, and F); $20 \mu \mathrm{m}$ (E); $40 \mu \mathrm{m}$ (G $-\mathrm{L})$. using the Cell Death Detection ELISA Kit (Roche, Mannheim, Germany), with results normalized to the DNA content in cell lysates using a Quant-iT DNA Assay Kit (Molecular Probes, Eugene, OR) and expressed as the ratio of OD/DNA content.

\section{Statistical Analysis}

Data are shown as means $\pm \mathrm{SD}$. Data were analyzed by oneway analysis of variance with the Tukey multiple comparison test using GraphPad Prism 8.0 software (GraphPad Software, San Diego, CA).

\section{Results}

\section{Pharmacologic JNK Inhibition Prevents IRI-Induced AKI}

Vehicle-treated rats developed severe acute kidney injury at 24 hours after bilateral renal IRI based on a marked 

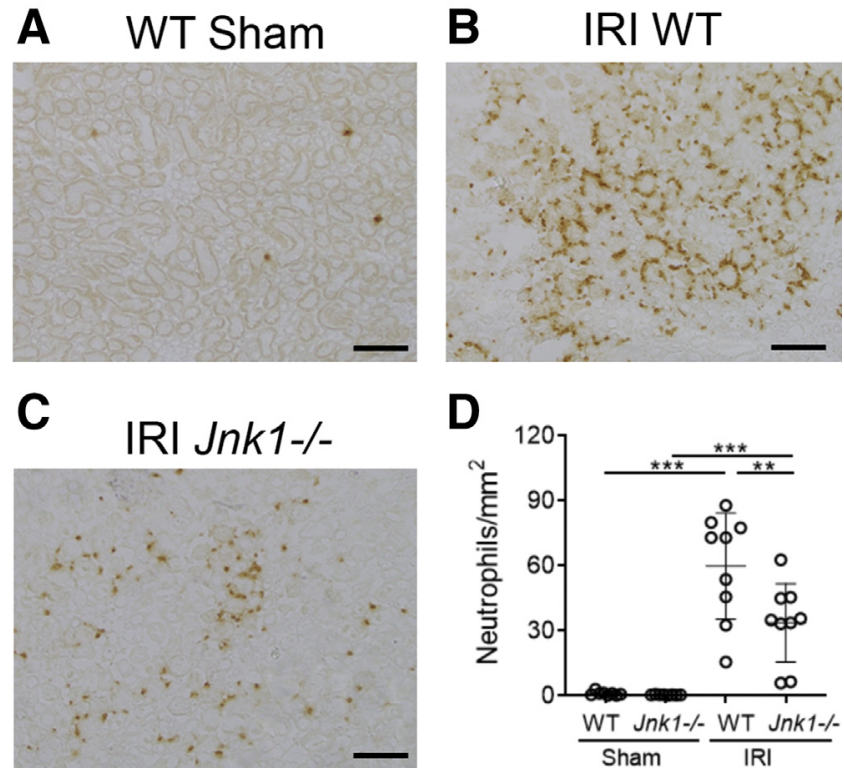

Figure 5 JNK1 promotes neutrophil infiltration. Groups of wild-type (WT) and $J n k 1^{-/-}$mice underwent bilateral ischemic/reperfusion injury (IRI), or a sham procedure. A-C: Immunostaining for neutrophils in the outer medulla. A: WT sham control, showing occasional neutrophils. B: WT IRI, showing many infiltrating neutrophils around damaged tubules. C: Jnk1 ${ }^{-/-}$IRI shows significant, but reduced, neutrophil infiltration. D: Quantification of neutrophil infiltration. One-way analysis of variance with the Tukey multiplecomparisons test was performed. ${ }^{* *} P<0.01,{ }^{* * *} P<0.001$. Scale bars $=100 \mu \mathrm{m}(\mathbf{A}-\mathbf{C})$.

increase in serum creatinine and blood urea nitrogen levels (Figure 1, A and B). This was associated with pronounced histologic damage, including extensive tubular necrosis (Figure 1, C-E). Tubular damage was also evident by upregulation of the tubular damage marker, Kim1/Hacvrl (Figure 2E), and considerable tubular cell death, as shown by TUNEL staining (Figure 2, A, B and D). Vehicletreated IRI showed a substantial neutrophil infiltrate based on immunostaining and increased Elane mRNA levels (Supplemental Figure S2, A and B, and Figure 2F), as well as a significant infiltrate of macrophages (Supplemental Figure S2, D and E) with increased mRNA levels of $C d 68$ and the macrophage activation marker, Nos2 (Figure 2, G and H). There was also up-regulation of the inflammatory cytokine, $\operatorname{Tnf}$ (Figure 2I).

Because CC-930 does not prevent JNK phosphorylation, ${ }^{11}$ phosphorylation of JUN at Ser63 was examined as a readout of JNK activity. Only occasional cells exhibited p-JUN staining in the sham control. By contrast, many tubular epithelial cells exhibited p-JUN staining in the vehicle-treated IRI group (Figure 3, A and B). By comparison, CC-930 treatment substantially reduced the number of $\mathrm{p}-\mathrm{JUN}^{+}$cells, as shown by immunostaining and Western blot analysis (Figure 3, C-E). CC-930 treatment provided substantial protection against acute kidney injury, as shown by much lower serum creatinine and blood urea nitrogen levels (Figure 1, A and B), less histologic damage (Figure 1,
$\mathrm{C}$ and F), reduced Kiml/Havcrl mRNA levels (Figure 2E), and fewer TUNEL ${ }^{+}$cells (Figure 2, C and D). In addition, CC-930 treatment significantly reduced the neutrophil and macrophage infiltration (Supplemental Figure S2, C and F) and expression of Nos2 and Tnf (Figure 2, E-I).

\section{Jnk1 ${ }^{-/}$Mice Are Protected from IRI-Induced AKI}

Because CC-930 inhibited virtually all JNK activity in the IRI model, a genetic approach was used to examine the relative contribution of JNK1 versus JNK2. The response of WT and $J n k 1^{-1-}$ mice was compared in a 24-hour model of bilateral IRI-induced acute kidney injury. WT mice developed acute kidney injury 24 hours after IRI, as shown by increased levels of serum creatinine and blood urea nitrogen, histologic tubular damage, and tubular cell death, as identified by TUNEL and cleaved caspase 3 staining (Figure 4, A-E, G, H, J, K, and $\mathrm{M}-\mathrm{O}$ ). This tubular damage was associated with a substantial neutrophil infiltrate in the outer medulla and inner cortex (Figure 5, A and B).

In contrast, $J n k 1^{-1-}$ mice showed significant protection from acute kidney injury in the renal IRI model based on lower levels of serum creatinine and blood urea nitrogen (Figure 4, A and B). Jnk-1 $1^{-1-}$ mice also showed less severe histologic tubular damage as well as a reduction in tubular cell death identified by TUNEL and cleaved caspase 3 staining (Figure 4, F, I, and L-O). Furthermore, $J n k 1^{-1-}$ mice exhibited less neutrophil infiltration (Figure 5, C and D).

\section{Jnk2 ${ }^{-/-}$Mice Are Not Protected from IRI-Induced AKI}

Wild-type and $J n k 2^{-/-}$mice were examined in a 24-hour model of bilateral IRI. Compared with the marked increase in JUN phosphorylation seen in the WT IRI group by Western blot analysis, $J n k 2^{-/-}$mice showed an approximately 50\% reduction in JUN phosphorylation (Figure 6, C and D). However, $J n k 2^{-/-}$mice were not protected from the development of severe kidney injury following IRI based on serum creatinine and blood urea nitrogen levels (Figure 7, A and B), tubular damage, and Kim1/Havcrl levels (Figure 7, C, E, and F). Similarly, Jnk2 $2^{-/}$mice were not protected from neutrophil or macrophage infiltration (Supplemental Figure $\mathrm{S} 3, \mathrm{~A}-\mathrm{C}$ and $\mathrm{E}-\mathrm{G}$, and Figure 8, A and $\mathrm{B}$ ) or the up-regulation of $C c l 2$, Nos2, Tnf, or Il6 mRNA levels (Figure 8, C-F).

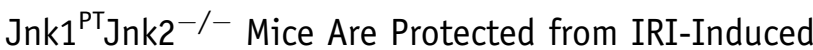 AKI}

The protection of $J n k 1^{-/-}$mice in the renal IRI model could be due to JNK1 facilitating tubular cell necrosis and/or JNK1 in neutrophils and macrophages facilitating their recruitment and activation in the injured kidney. To address the first possibility, mice lacking Jnkl in proximal tubules 

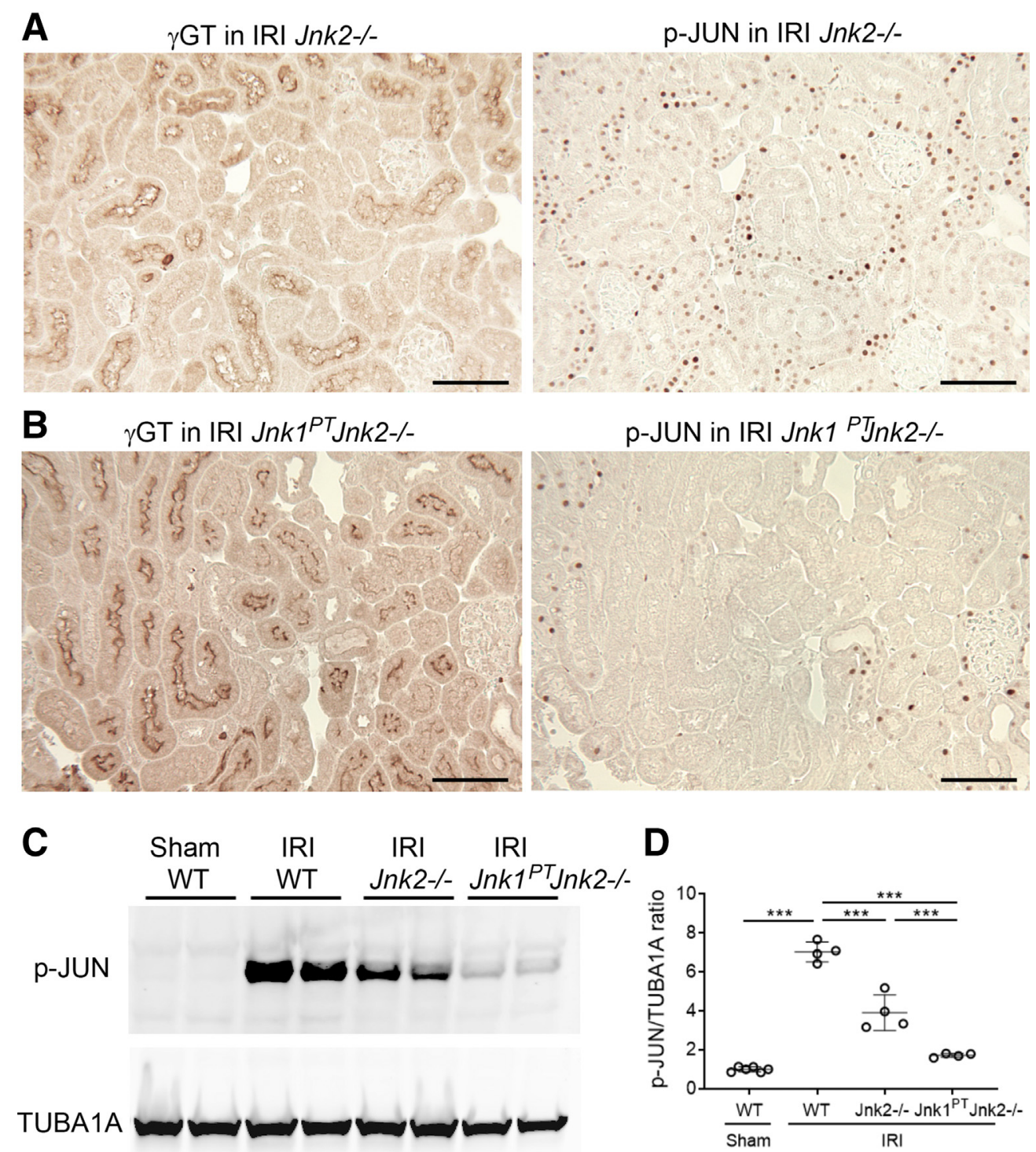

Figure 6 JNK signaling in ischemic/reperfusion injury (IRI). Mice of different genotypes were sacrificed 30 minutes after reperfusion. A: Serial sections from a Jnk1 ${ }^{f / f} J n k 2^{-/-}$mouse, showing brush border staining for $\gamma$-glutamyltransferase $(\gamma \mathrm{GT})$ and nuclear staining for phosphorylated JUN ( $p$-JUN) Ser63. Many tubules show p-JUN staining, including many $\gamma \mathrm{GT}^{+}$tubules. B: Serial sections from a Jnk1 $1^{P T} J n k 2^{-/-}$mouse, showing staining for $\gamma \mathrm{GT}$ and $\mathrm{p}-\mathrm{JUN}$ Ser63. There is a lack of $\mathrm{p}$-JUN staining in $\gamma \mathrm{GT}^{+}$tubules, although some other tubules show p-JUN staining. C: Western blot analysis of p-JUN with TUBA1A/tubulin control for sham and 30-minute IRI groups. D: Quantification of p-JUN Western blot analysis. One-way analysis of variance with the Tukey multiplecomparisons test was performed. ${ }^{* *} P<0.001$. Scale bars $=100 \mu \mathrm{m}(\mathbf{A}$ and $\mathbf{B})$. WT, wild type.

$\left(J_{n k} l^{f f f} \gamma G T^{C r e}\right.$ mice, termed $\left.J n k l^{P T}\right)$ were generated on the

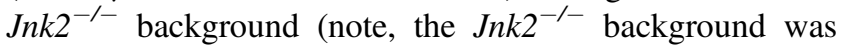
employed before it was known that JNK2 plays no role in the IRI model).

First, a pilot study was performed to assess JNK signaling at 30 minutes after reperfusion, a time of maximal JNK activation and before the loss of tubular morphology. ${ }^{8} \mathrm{Jnkl}^{\mathrm{fl}}$ ${ }^{f} J n k 2^{-/-}$mice showed a strong induction of JUN Ser63 staining at 30 minutes in most tubular segments, including $\gamma$ GT stained proximal tubules, in the inner cortex and outer medulla (Figure 6A). By contrast, Jnk1 ${ }^{P T} J n k 2^{-/-}$mice showed a major reduction in p-JUN Ser63 staining in $\gamma \mathrm{GT}^{+}$proximal tubules at 30 minutes after reperfusion, although staining in other tubular segments was still apparent (Figure 6B). Western blot analysis of kidneys showed an almost complete inhibition of JUN phosphorylation in $J n k 1^{P T} J n k 2^{-\prime-}$ mice (Figure 7, Figure $6 \mathrm{C}$ and D).

Compared with the severe renal dysfunction seen in WT and $J n k 2^{-/-}$mice at 24 hours after IRI, $J n k 1^{P T} J n k 2^{-/-}$mice showed a marked reduction in serum creatinine and blood urea levels (Figure 7, A and B). In addition, $J n k 1^{P T} J n k 2^{-/-}$ mice showed less histologic tubular damage and a reduction in Kim1/Haverl mRNA levels (Figure 7, D-F). Furthermore, $J n k 1^{P T} J n k 2^{-/-}$mice showed a reduction in neutrophil and macrophage infiltration (Supplemental Figure S3, D and $\mathrm{H}$, and Figure 8, A and B) and a reduction in Ccl2, Nos2, 
A

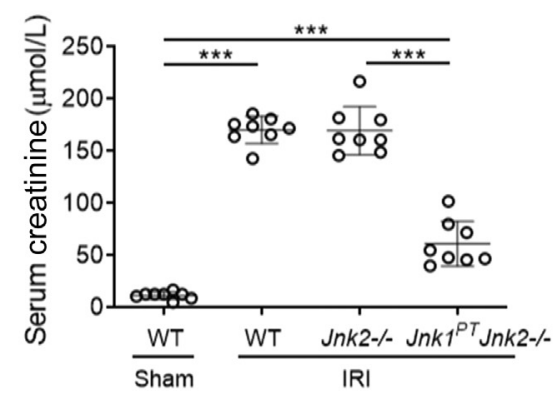

c Jnk2-/- IRI

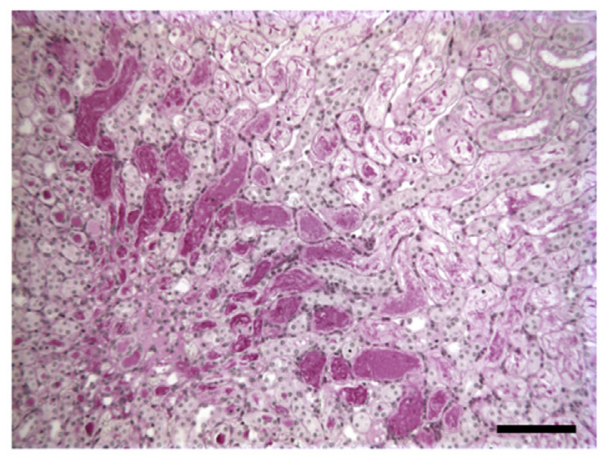

E

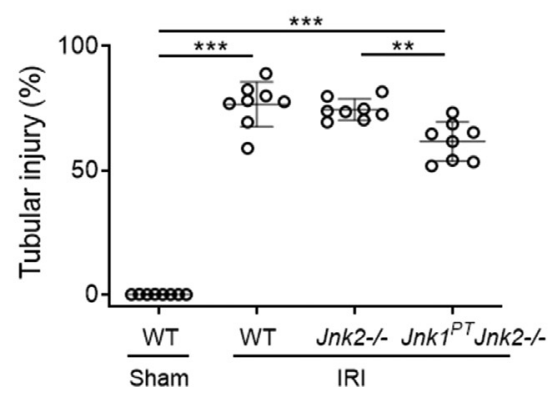

B
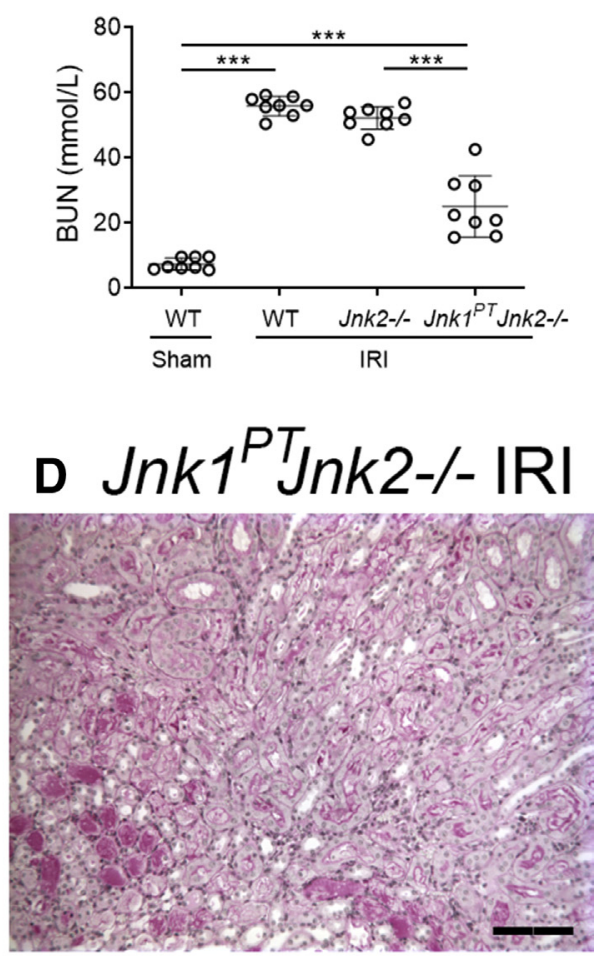

$\mathbf{F}$

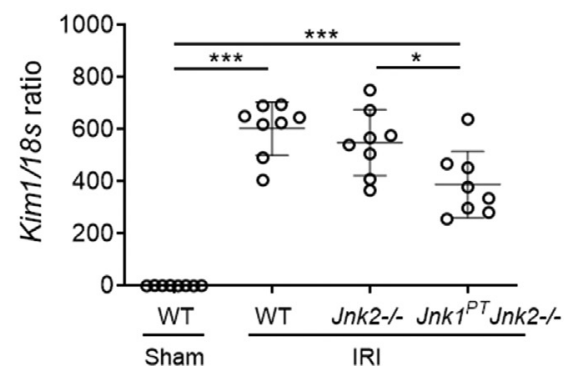

Figure 7 JNK1 in proximal tubules promotes acute kidney injury. Groups of wild-type (WT), Jnk2 ${ }^{-/-}$, and Jnk1 ${ }^{P T} J n k 2^{-/-}$mice underwent bilateral ischemic/reperfusion injury (IRI), with WT sham mice as controls. A: Serum creatinine. B: Blood urea nitrogen (BUN). C and D: Periodic acid-Schiff staining of kidney sections. C: Jnk2 $2^{-1}$ IRI, showing extensive tubular damage with loss of brush border, nuclear loss, sloughing of cells into the lumen, and cast formation. D: Jnk1 $1^{P T} J n k 2^{-/-}$IRI, showing significant, but reduced, tubular damage. E: Percentage of tubules showing injury. F: Real-time PCR for Kim1/Havcr1 mRNA levels. One-way analysis of variance with the Tukey multiple-comparisons test was performed. ${ }^{*} P<0.05,{ }^{* *} P<0.01$, and ${ }^{* * *} P<0.001$. Scale bars $=100 \mu \mathrm{m}(\mathbf{C}$ and $\mathbf{D})$.

and $I l 6$ mRNA levels; however, the reduction in $\operatorname{Tnf}$ mRNA levels seen compared with WT IRI mice did not reach statistical significance compared with the $J n k 2^{-/-}$IRI group (Figure 8, C-F).

\section{JNK1 Activates the RIP3/MLKL Pathway of Necroptosis in Tubular Epithelial Cells}

The role of JNK1 and JNK2 in oxidant-induced cell death was investigated in primary cultures of tubular epithelial cells isolated from $J n k 1^{-/-}, J n k 2^{-/-}$, and WT mice. Tubular cells from WT and $J n k 2^{-/-}$mice showed an equivalent dose-dependent increase in cell death in response to hydrogen peroxide stimulation, whereas $J n k 1^{-1-}$ tubular cells were significantly protected against cell death (Figure 9A). CC-930 treatment significantly reduced hydrogen peroxide-induced cell death in both WT and $J n k 2^{-/-}$cells (Figure 9, B and D), whereas no further protection against cell death was seen in $\mathrm{nkl}^{-/-}$cells (Figure 9C). Components of the necroptosis pathway were examined at 4 hours after hydrogen peroxide stimulation in cultured tubular epithelial cells. Both WT and $J n k 2^{-1-}$ cells showed hydrogen peroxide-induced phosphorylation of RIP3 and MLKL, but this was absent in $J n k 1^{-1-}$ cells (Figure 10). 
A

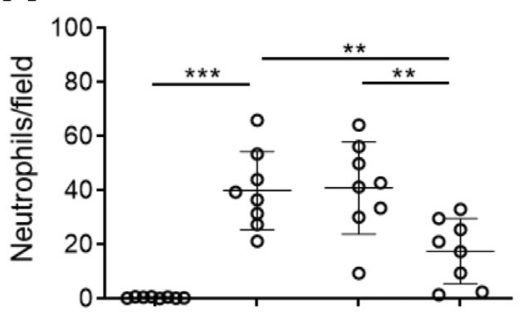

C

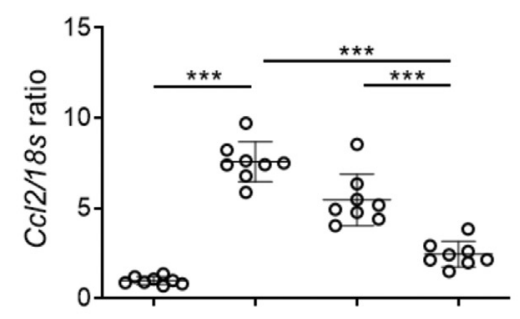

E

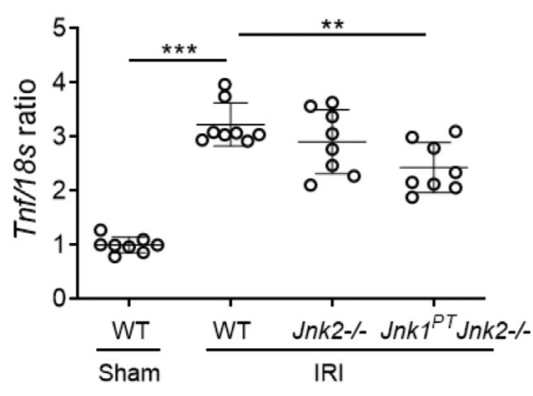

B

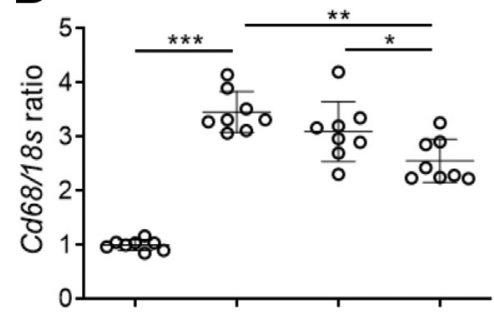

D

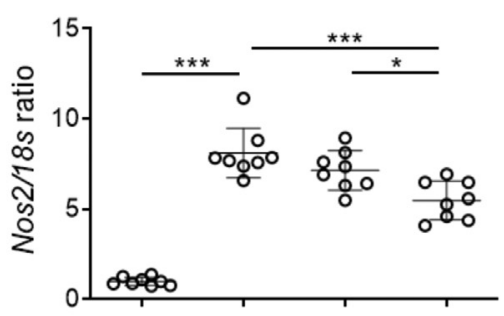

$\mathbf{F}$

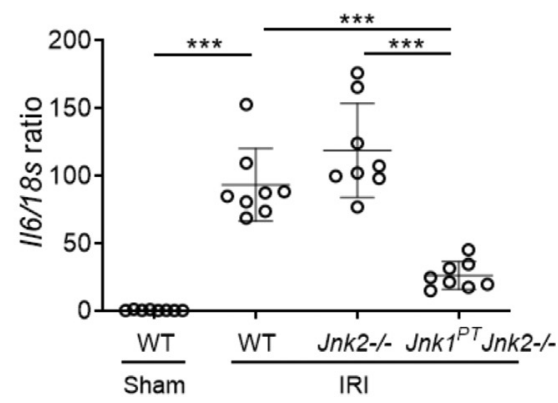

Figure 8 JNK1 in proximal tubules promotes renal inflammation. Groups of wild-type (WT), $J n k 2^{-/-}$, and $J n k 1^{P T} J n k 2^{-/-}$mice underwent bilateral ischemic/reperfusion injury (IRI), with WT sham mice as controls. A: Quantification of immunostaining for neutrophils. B-F: Real-time PCR analysis of kidney mRNA levels of Cd68 (B), Ccl2 (C), Nos2 (D), Tnf (E), and Il6 (F). One-way analysis of variance with the Tukey multiplecomparisons test was performed. ${ }^{*} P<0.05$, ${ }^{* * P}<0.01$, and ${ }^{* * *} P<0.001$.

\section{Discussion}

This study has demonstrated that pharmacologic inhibition of JNK signaling provides substantial protection against IRI-induced acute renal failure. Genetic studies identified that it is the JNK1 enzyme within the proximal tubule that plays a key role in the development of acute renal failure following IRI.

The demonstration that CC-930 provides substantial protection against acute renal failure following IRI provides significant new information. Wang et $\mathrm{al}^{9}$ showed that treatment with the JNK inhibitor SP600125 provides significant protection against acute renal failure in a rat bilateral IRI model. However, SP600125 is not selective for JNK as it inhibits 22 other kinases with equal or greater potency than JNK isoforms. ${ }^{20,21}$ Previous studies with CC-401 used a mild model of rat bilateral IRI in which serum creatinine was increased only 2.5 -fold. ${ }^{8}$ Therefore, this finding was replicated in the more challenging situation of severe IRI and CC-930 JNK inhibitor was used as it has greater potency and a considerably longer half-life compared with CC-401. ${ }^{11,22}$ In the current study, the rat IRI model induced a 5.4-fold increase in serum creatinine at 24 hours after IRI, and CC-930 treatment reduced serum creatinine levels by $60 \%$. Furthermore, CC-930 treatment was effective in inhibiting JNK signaling, reducing tubular damage and necrosis, and reducing leukocyte infiltration and inflammation. These findings support the potential for a pharmacologic approach to preventing anticipated renal IRI-induced acute renal failure.

Previous studies have shown a considerable redundancy between JNK1 and JNK2 signaling in terms of JUN phosphorylation in tubular cells in the obstructed mouse kidney. In the current study, both JNK1 and JNK2 made a substantial contribution to JNK signaling in the kidney following IRI. Genetic deletion of Jnk2 reduced JUN phosphorylation by approximately $50 \%$, and then combined $J n k 2$ deletion and $J n k l$ deletion in the proximal tubule reduced JUN phosphorylation by approximately $90 \%$. However, global Jnk1, but not Jnk2, deletion provided substantial protection against IRI-induced acute renal failure. This finding was supported by in vitro studies showing protection of $J n k 1^{-1-}$, but not $J n k 2^{-/-}$, tubular cells from reactive oxygen species-induced cell death. 
A

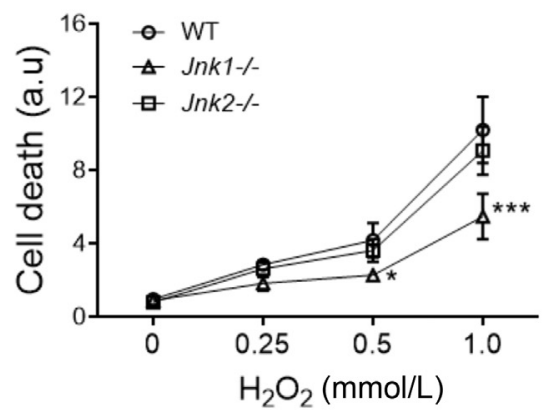

C

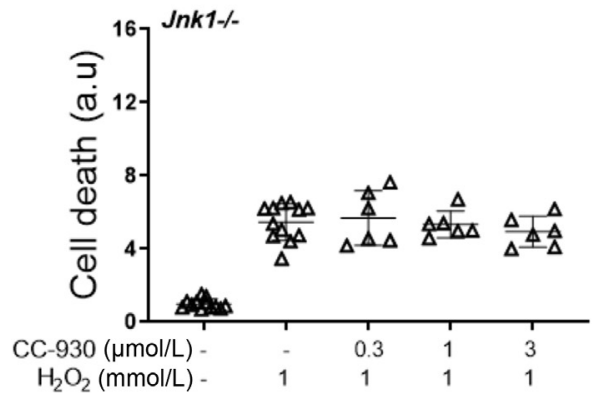

B

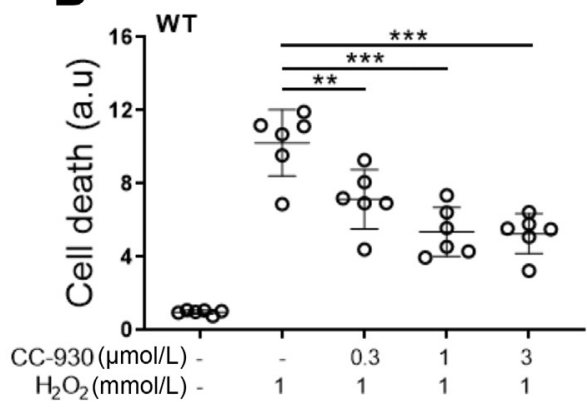

D

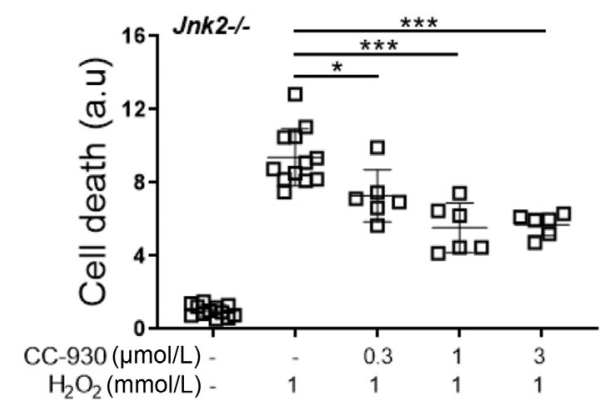

Figure 9 JNK1 promotes tubular cell death. Primary tubular cells were cultured from wild-type (WT), Jnk1 ${ }^{-{ }^{-}}$, and Jnk2 ${ }^{-{ }^{-}}$mice. A: Tubular cell death induced by varying doses of hydrogen peroxide. B-D: Tubular cell death induced by $1 \mathrm{mmol} / \mathrm{L} \mathrm{H}_{2} \mathrm{O}_{2}$ with or without CC-930 in WT cells (B), Jnk1 ${ }^{-/-}$cells (C), and $\mathrm{Jnk2} 2^{-/-}$cells (D). One-way analysis of variance with the Tukey multiple-comparisons test was performed. ${ }^{*} P<0.05,{ }^{*} P<0.01$, and ${ }^{* * * P}<0.001$. a.u., arbitrary unit.

The finding that JNK1, and not JNK2, mediates IRIinduced acute renal failure is consistent with some, but not other, studies of nonrenal IRI. Jnk $2^{-/}$mice show protection in a model of liver IRI. ${ }^{23}$ In addition, in a liver transplant model, donor $J n k 2^{-1-}$ organs showed reduced damage and survived longer compared with wild-type livers. ${ }^{24}$ By contrast, in a cardiac model of IRI, both $J n k 1^{-\prime-}$ and $J n k 2^{-\prime-}$ mice showed significantly reduced
A

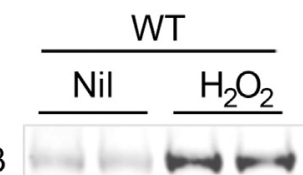

p-RIP3

TUBA1A

p-MLKL

TUBA1A
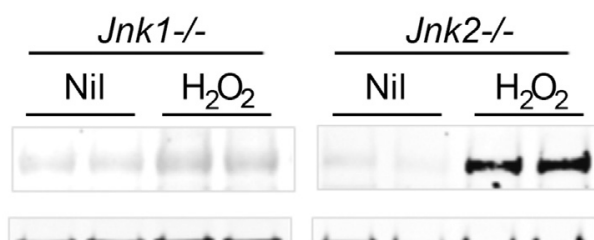

B

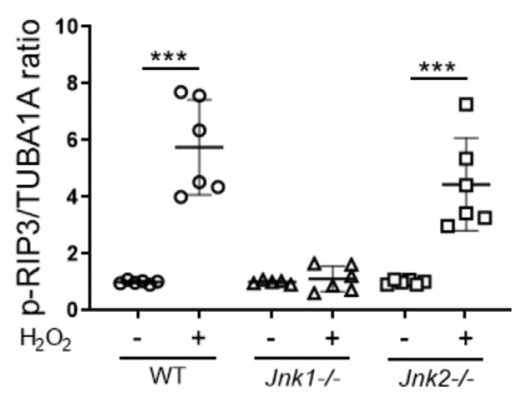

C

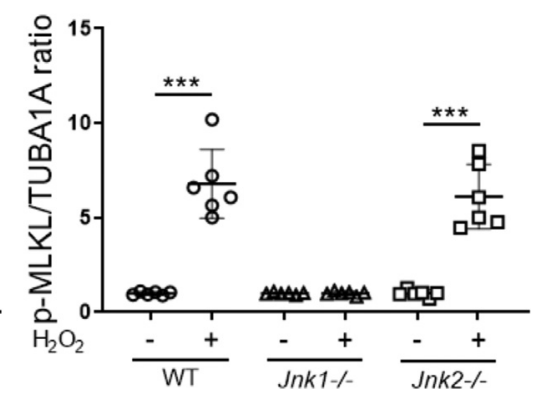

Figure 10 JNK1 induces receptor interacting serine/ threonine kinase 3 (RIP3)/mixed lineage kinase domainlike pseudokinase (MLKL) activation in tubular cells. Primary tubular cells were cultured from wild-type (WT), $J n k 1^{-/-}$, and $J n k 2^{-/-}$mice. A: Western blot analysis of RIP3 phosphorylation and MLKL phosphorylation in tubular cells 4 hours after stimulation with $1 \mathrm{mmol} / \mathrm{L} \mathrm{H}_{2} \mathrm{O}_{2}$ with TUBA1A/tubulin control. B: Quantification of phosphorylated RIP3 (p-RIP3) blots. C: Quantification of phosphorylated MLKL ( $p-M L K L)$ blots. One-way analysis of variance with the Tukey multiple-comparisons test was performed. ${ }^{* * *} P<0.001$. 
myocardial damage. ${ }^{25}$ However, the current findings are consistent with a previous study in the obstructed kidney in which tubular cell apoptosis was significantly reduced in $J n k 1^{-/-}$mice, but not in $J n k 2^{-/-}$mice. ${ }^{4}$

Studies using CC-930 treatment and global $J n k 1^{-1-}$ mice indicate that systemic blockade of JNK not only reduces tubular cell necrosis, but also reduces neutrophil and macrophage infiltration, macrophage activation, and general markers of inflammation. The question is whether JNK signaling is important in multiple cell types in renal IRI. Although JNK signaling, as assessed by JUN phosphorylation, occurred predominantly in tubular epithelial cells in the IRI kidney, it does not preclude the importance of JNK signaling in infiltrating leukocytes because activation of this pathway may be transient and therefore difficult to detect by immunostaining. For example, JNK signaling is important for inducing a proinflammatory macrophage phenotype and renal injury in experimental glomerulonephritis, ${ }^{18,26}$ whereas JNK inhibition in adoptively transferred macrophages is sufficient to prevent acute macrophage-mediated glomerular injury. ${ }^{27}$ However, a pathogenic role for macrophages in the induction of acute renal injury following IRI is uncertain. ${ }^{28} \mathrm{Jnkl}$ deletion in the proximal tubule was effective in reducing tubular cell damage and death as well as reducing neutrophil and macrophage infiltration, macrophage activation, and inflammatory markers. Thus, preventing the release of danger-associated molecular patterns from injured and dying tubular cells may be of greater importance in driving the leukocyte infiltration and activation than JNK activation per se in these cells, although studies of JNK deletion in myeloid cells to confirm this have yet to be performed.

Given that $J n k 1^{-1-}$, but not $J n k 2^{-/-}$, mice were protected in the renal IRI model, it follows that there is a specific JNK1 target involved in the induction of tubular cell death. A central role for the necroptosis pathway in mediating IRI-induced acute kidney injury has been shown by using mice lacking the key enzymes RIP3 or MLKL and the use of the RIP1 inhibitor Necrostatin- $1 .{ }^{29,30}$ In the in vitro studies, deletion of $J n k 1$, but not Jnk2, in tubular cells prevented activation (phosphorylation) of RIP3 and MLKL at 4 hours after exposure of cells to reactive oxygen species. This indicates that JNK1 signaling is an early and essential component of the necroptosis pathway in tubular cells exposed to oxidative stress. Studies in other cell types and other animal models have shown that JNK and RIP3/ MLKL act in an amplification loop to promote necroptotic cell death. ${ }^{31,32}$ However, this is the first study to demonstrate that JNK1 is required for RIP3 and MLKL activation in a necroptotic pathway. Further studies are required to identify the intermediate steps between JNK1 activation and RIP3 activation. One limitation of these in vitro studies is that they focus on oxidative stress-induced cell death without examining ischemia, an important cause of cell death in the IRI model.
In conclusion, the current study demonstrates that JNK1, but not JNK2, plays a critical role in acute renal failure following IRI. In particular, JNK1 activation in the proximal tubule promotes tubular cell damage and necrosis, with cell culture studies identifying a role for JNK1 in activation of the RIP3/MLKL pathway of necroptosis. Finally, pharmacologic blockade of JNK signaling has therapeutic potential for prevention of anticipated renal ischemia/reperfusion injury.

\section{Acknowledgments}

We thank Prof. Eric Neilson (Vanberbilt University Medical Center, Nashville, TN) for kindly providing $\gamma$-glutamyltransferase-Cre mice; and Celgene for providing CC-930 for these studies.

\section{Supplemental Data}

Supplemental material for this article can be found at http://doi.org/10.1016/j.ajpath.2021.02.004.

\section{References}

1. Zuk A, Bonventre JV: Acute kidney injury. Annu Rev Med 2016, 67: 293-307

2. Desanti De Oliveira B, Xu K, Shen TH, Callahan M, Kiryluk K, D'Agati VD, Tatonetti NP, Barasch J, Devarajan P: Molecular nephrology: types of acute tubular injury. Nat Rev Nephrol 2019, 15 : 599-612

3. Weston CR, Davis RJ: The JNK signal transduction pathway. Curr Opin Cell Biol 2007, 19:142-149

4. Ma FY, Flanc RS, Tesch GH, Han Y, Atkins RC, Bennett BL, Friedman GC, Fan JH, Nikolic-Paterson DJ: A pathogenic role for cJun amino-terminal kinase signaling in renal fibrosis and tubular cell apoptosis. J Am Soc Nephrol 2007, 18:472-484

5. Tournier C, Hess P, Yang DD, Xu J, Turner TK, Nimnual A, BarSagi D, Jones SN, Flavell RA, Davis RJ: Requirement of JNK for stress-induced activation of the cytochrome c-mediated death pathway. Science 2000, 288:870-874

6. Ma Q, Devarajan P: Induction of proapoptotic Daxx following ischemic acute kidney injury. Kidney Int 2008, 74:310-318

7. Pat BK, Cuttle L, Watters D, Yang T, Johnson DW, Gobe GC: Fibrogenic stresses activate different mitogen-activated protein kinase pathways in renal epithelial, endothelial or fibroblast cell populations. Nephrology (Carlton) 2003, 8:196-204

8. Kanellis J, Ma FY, Kandane-Rathnayake R, Dowling JP, Polkinghorne KR, Bennett BL, Friedman GC, Nikolic-Paterson DJ: JNK signaling in human and experimental renal ischaemia/reperfusion injury. Nephrol Dial Transpl 2010, 25:2898-2908

9. Wang Y, Ji HX, Xing SH, Pei DS, Guan QH: SP600125, a selective JNK inhibitor, protects ischemic renal injury via suppressing the extrinsic pathways of apoptosis. Life Sci 2007, 80:2067-2075

10. Lim AK, Ma FY, Nikolic-Paterson DJ, Ozols E, Young MJ, Bennett BL, Friedman GC, Tesch GH: Evaluation of JNK blockade as an early intervention treatment for type 1 diabetic nephropathy in hypertensive rats. Am J Nephrol 2011, 34:337-346

11. Plantevin Krenitsky V, Nadolny L, Delgado M, Ayala L, Clareen SS, Hilgraf R, Albers R, Hegde S, D’Sidocky N, Sapienza J, Wright J, McCarrick M, Bahmanyar S, Chamberlain P, Delker SL, Muir J, Giegel D, Xu L, Celeridad M, Lachowitzer J, Bennett B, Moghaddam M, Khatsenko O, Katz J, Fan R, Bai A, Tang Y, 
Shirley MA, Benish B, Bodine T, Blease K, Raymon H, Cathers BE, Satoh Y: Discovery of CC-930, an orally active anti-fibrotic JNK inhibitor. Bioorg Med Chem Lett 2012, 22:1433-1438

12. Das M, Jiang F, Sluss HK, Zhang C, Shokat KM, Flavell RA, Davis RJ: Suppression of p53-dependent senescence by the JNK signal transduction pathway. Proc Natl Acad Sci U S A 2007, 104: $15759-15764$

13. Iwano M, Plieth D, Danoff TM, Xue C, Okada H, Neilson EG: Evidence that fibroblasts derive from epithelium during tissue fibrosis. J Clin Invest 2002, 110:341-350

14. Leong KG, Ozols E, Kanellis J, Nikolic-Paterson DJ, Ma FY: Cyclophilin A promotes inflammation in acute kidney injury but not in renal fibrosis. Int J Mol Sci 2020, 21:3667

15. Ryan J, Kanellis J, Blease K, Ma FY, Nikolic-Paterson DJ: Spleen tyrosine kinase signaling promotes myeloid cell recruitment and kidney damage after renal ischemia/reperfusion injury. Am J Pathol 2016, 186:2032-2042

16. Masaki T, Foti R, Hill PA, Ikezumi Y, Atkins RC, NikolicPaterson DJ: Activation of the ERK pathway precedes tubular proliferation in the obstructed rat kidney. Kidney Int 2003, 63: $1256-1264$

17. Ma FY, Tesch GH, Nikolic-Paterson DJ: ASK1/p38 signaling in renal tubular epithelial cells promotes renal fibrosis in the mouse obstructed kidney. Am J Physiol Ren Physiol 2014, 307:F1263-F1273

18. Ma FY, Flanc RS, Tesch GH, Bennett BL, Friedman GC, NikolicPaterson DJ: Blockade of the c-Jun amino terminal kinase prevents crescent formation and halts established anti-GBM glomerulonephritis in the rat. Lab Invest 2009, 89:470-484

19. Ma FY, Tesch GH, Flavell RA, Davis RJ, Nikolic-Paterson DJ: MKK3-p38 signaling promotes apoptosis and the early inflammatory response in the obstructed mouse kidney. Am J Physiol Ren Physiol 2007, 293:F1556-F1563

20. Bain J, McLauchlan H, Elliott M, Cohen P: The specificities of protein kinase inhibitors: an update. Biochem J 2003, 371:199-204

21. Bain J, Plater L, Elliott M, Shpiro N, Hastie CJ, McLauchlan H, Klevernic I, Arthur JS, Alessi DR, Cohen P: The selectivity of protein kinase inhibitors: a further update. Biochem J 2007, 408:297-315

22. Abdolazimi Y, Zhao Z, Lee S, Xu H, Allegretti P, Horton TM, Yeh B, Moeller HP, Nichols RJ, McCutcheon D, Shalizi A, Smith M, Armstrong NA, Annes JP: CC-401 promotes beta-cell replication via pleiotropic consequences of DYRK1A/B inhibition. Endocrinology 2018, 159:3143-3157

23. Devey L, Mohr E, Bellamy C, Simpson K, Henderson N, Harrison EM, Ross JA, Wigmore SJ: c-Jun terminal kinase-2 gene deleted mice overexpress hemeoxygenase-1 and are protected from hepatic ischemia reperfusion injury. Transplantation 2009, 88: 308-316

24. Theruvath TP, Czerny C, Ramshesh VK, Zhong Z, Chavin KD, Lemasters JJ: C-Jun N-terminal kinase 2 promotes graft injury via the mitochondrial permeability transition after mouse liver transplantation. Am J Transpl 2008, 8:1819-1828

25. Kaiser RA, Liang Q, Bueno O, Huang Y, Lackey T, Klevitsky R, Hewett TE, Molkentin JD: Genetic inhibition or activation of JNK1/2 protects the myocardium from ischemia-reperfusion-induced cell death in vivo. J Biol Chem 2005, 280:32602-32608

26. Flanc RS, Ma FY, Tesch GH, Han Y, Atkins RC, Bennett BL, Friedman GC, Fan JH, Nikolic-Paterson DJ: A pathogenic role for JNK signaling in experimental anti-GBM glomerulonephritis. Kidney Int 2007, 72:698-708

27. Ikezumi Y, Hurst L, Atkins RC, Nikolic-Paterson DJ: Macrophagemediated renal injury is dependent on signaling via the JNK pathway. J Am Soc Nephrol 2004, 15:1775-1784

28. Ferenbach DA, Sheldrake TA, Dhaliwal K, Kipari TM, Marson LP, Kluth DC, Hughes J: Macrophage/monocyte depletion by clodronate, but not diphtheria toxin, improves renal ischemia/reperfusion injury in mice. Kidney Int 2012, 82:928-933

29. Linkermann A, Brasen JH, Darding M, Jin MK, Sanz AB, Heller JO, De Zen F, Weinlich R, Ortiz A, Walczak H, Weinberg JM, Green DR, Kunzendorf U, Krautwald S: Two independent pathways of regulated necrosis mediate ischemia-reperfusion injury. Proc Natl Acad Sci U S A 2013, 110:12024-12029

30. Newton K, Dugger DL, Maltzman A, Greve JM, Hedehus M, MartinMcNulty B, Carano RA, Cao TC, van Bruggen N, Bernstein L, Lee WP, Wu X, DeVoss J, Zhang J, Jeet S, Peng I, McKenzie BS, Roose-Girma M, Caplazi P, Diehl L, Webster JD: Vucic D: RIPK3 deficiency or catalytically inactive RIPK1 provides greater benefit than MLKL deficiency in mouse models of inflammation and tissue injury. Cell Death Differ 2016, 23:1565-1576

31. Gautheron J, Vucur M, Reisinger F, Cardenas DV, Roderburg C, Koppe C, Kreggenwinkel K, Schneider AT, Bartneck M, Neumann UP, Canbay A, Reeves HL, Luedde M, Tacke F, Trautwein C, Heikenwalder M, Luedde T: A positive feedback loop between RIP3 and JNK controls non-alcoholic steatohepatitis. EMBO Mol Med 2014, 6:1062-1074

32. Hu W, Wu X, Yu D, Zhao L, Zhu X, Li X, Huang T, Chu Z, Xu Y: Regulation of JNK signaling pathway and RIPK3/AIF in necroptosismediated global cerebral ischemia/reperfusion injury in rats. Exp Neurol 2020, 331:113374 